\title{
Factors Associated With Parental Activation in Pediatric Hematopoietic Stem Cell Transplant
}

\author{
Brian W. Pennarola ${ }^{1}$, Angie Mae Rodday ${ }^{1}$, Deborah K. Mayer ${ }^{2}$, Sara J. Ratichek ${ }^{1}$, Stella M. \\ Davies $^{3}$, Karen L. Syrjala ${ }^{4}$, Sunita Patel ${ }^{5}$, Kristin Bingen ${ }^{6}$, Mary Jo Kupst ${ }^{6}$, Lisa Schwartz ${ }^{7}$, \\ Eva C. Guinan ${ }^{8}$, Judith H. Hibbard ${ }^{9}$, and Susan K. Parsons ${ }^{1}$ for the HSCT-CHESS Study ${ }^{*}$ \\ ${ }^{1}$ Tufts Medical Center, Boston, MA, USA \\ ${ }^{2}$ The University of North Carolina at Chapel Hill, Chapel Hill, NC, USA \\ ${ }^{3}$ Cincinnati Children's Hospital Medical Center, Cincinnati, OH, USA \\ ${ }^{4}$ Fred Hutchinson Cancer Research Center, Seattle, WA, USA \\ ${ }^{5}$ City of Hope National Medical Center, Duarte, CA, USA \\ ${ }^{6}$ Medical College of Wisconsin, Milwaukee, WI, USA \\ ${ }^{7}$ Children's Hospital of Philadelphia, Philadelphia, PA, USA \\ ${ }^{8}$ Department of Pediatric Oncology, Dana-Farber Cancer Institute and Division of Hematology/ \\ Oncology, Childrens Hospital, Boston, MA, USA \\ ${ }^{9}$ University of Oregon, Eugene, OR, USA
}

\begin{abstract}
Patient activation, the extension of self-efficacy into self-management, is an essential component of effective chronic care. In pediatric populations, caregiver activation is also needed for proper disease management. This study investigates the relationships between parental activation and other characteristics of parent-child dyads $(N=198)$ presenting for pediatric hematopoietic stem cell transplant. Parental activation concerning their child's health was assessed using the Parent Patient Activation Measure (Parent-PAM), a modified version of the well-validated Patient Activation Measure (PAM). Using hierarchical linear regression and following the Belsky process model for determining parenting behaviors, a multivariate model was created for parental activation on behalf of their child that showed that the parent's age, rating of their own general health, self-activation, and duration of the child's illness were significantly related to Parent-PAM score. Our findings characterize a potentially distinct form of activation in a parent-child cohort preparing for a demanding clinical course.
\end{abstract}

(C) The Author(s) 2012

Corresponding Author: Susan K. Parsons, The Health Institute, ICRHPS, Tufts Medical Center, 800 Washington Street, \#345, Boston, MA 02111, USA, sparsons@ @uftsmedicalcenter.org.

* Please see the appendix for full listing of study staff and collaborators.

Declaration of Conflicting Interests

The authors declared no potential conflicts of interest with respect to the research, authorship, and/or publication of this article.

Reprints and permission: sagepub.com/journalsPermissions.nav 


\section{Keywords}

cancer; oncology; hematopoietic stem cell transplant (HSCT); children; patient activation; Patient Activation Measure

\section{Introduction}

In chronically ill populations, the effective interaction between clinicians and patients hinges on the active involvement of patients in their own health care (Wagner et al., 2001).

Expanding on the concept of self-efficacy, defined as a patient's judgment of their own ability to accomplish a desired goal (Bandura, 1982), patient activation more fully reflects a patient's level of involvement with their own health care. Achieving patient activation is a developmental process, requiring the progression from a fundamental belief in the importance of the patient role, to the possession of knowledge and confidence required to take action, to active change in behavior, and finally to maintain changes over time (Hibbard, Stockard, Mahoney, \& Tusler, 2004).

Extensive research shows that patient activation and the related construct of self-efficacy in the context of disease management are powerful predictors of a range of clinical and psychosocial outcomes in chronically ill patients with a wide variety of diagnoses (Bodenheimer, Lorig, Holman, \& Grumbach, 2002; Han, Lee, Lee, \& Park, 2003). In populations with diabetes, baseline self-efficacy and improvement in self-efficacy over time were associated with positive health effects and increased adherence to a healthy lifestyle (Lorig, Ritter, \& Jacquez, 2005). Higher levels of self-motivation in diabetes care were also associated with maintained changes in diet and diligent blood glucose testing (Shigaki et al., 2010). In populations with cardiovascular conditions, higher activation promoted less frequent visits to primary care providers (Donald et al., 2010), greater adherence to medical regiments and dietary restrictions, and decreased number of hospital admissions (SchnellHoehn, Naimark, \& Tate, 2009). Similarly, patients with greater confidence in their ability to manage the symptoms of multiple sclerosis (Stepleman et al., 2010), arthritis (Osborne, Wilson, Lorig, \& McColl, 2007), and colostomy (Simmons, Smith, Bobb, \& Liles, 2007) have all been shown to experience lesser impact on daily living and increased health-related quality of life (HRQL).

Building on the integral role of an involved patient or individual in obtaining needed care, several studies have explored predictors of activation in chronically ill patients. Previous studies have identified significant positive associations between patient activation in chronically ill populations and two major sets of variables: patient HRQL, including patient emotional functioning, and specific demographic characteristics of the patient. Higher selfrating of general health (Hibbard \& Cunningham, 2008; Lubetkin, Lu, \& Gold, 2010; Stepleman et al., 2010), higher emotional functioning (Mosen et al., 2007), and lower depression status (Skolasky, Mackenzie, Wegener, \& Riley, 2008; Stepleman et al., 2010) have all been associated with higher patient activation. Additionally, significant associations have been observed between higher patient activation and higher level of education (Lubetkin et al., 2010), private insurance, and younger age (Hibbard \& Cunningham, 2008). 
Similar relationships have been outlined in studies of healthy populations where higher income, higher education, and better self-rated general health were associated with higher patient activation (Hibbard \& Cunningham, 2008; Lubetkin et al., 2010). Younger age and the possession of private insurance have also been positively associated with higher activation in the general population (Hibbard \& Cunningham, 2008).

For ill pediatric populations, parents adopt a significant role in the co-management of their child's care. Studies exploring self-efficacy and health management behaviors in parents of pediatric patients have illuminated the importance of an "activated" parent in achieving effective care. In a study of parent and adult-child dyads with hypertension, increased medical adherence in the adult-child dyad was associated with communication about the disease between the parent and child, the parent's confidence in their child's ability to properly self-manage, and the parent's own self-efficacy and knowledge concerning their own chronic care (Warren-Findlow, Seymour, \& Shenk, 2010). Parent self-efficacy has been implicated in positive health outcomes for both parent and child. In a study of children with sickle cell disease, parents with high self-efficacy concerning the importance of their role in management of their child's disease were more likely to request regular transcranial Doppler screenings for their children, which was shown to result in improved care (Bollinger, Nire, Rhodes, Chisolm, \& O'Brien, 2011). Low self-efficacy in parents of pediatric leukemia survivors was also a predictor of increased parental anxiety and avoidance (Best, Streisand, Catania, \& Kazak, 2001) and decreased adherence in the parents' own ability to practice healthy behaviors (Tucker, Butler, Loyuk, Desmond, \& Surrency, 2009). However, although studies have highlighted the critical importance of confident, self-efficacious parents who actively manage their child's health, parental activation on behalf of their child, an analogous construct to patient activation in chronically ill adults, has not to date been conceptualized or explored.

Because of the demanding regimen, extensive recovery period, and acute stress associated with the initial treatment, hematopoietic stem cell transplantation (HSCT) demands effective parent-child management and presents an ideal scenario for exploring the novel concept of parental activation. HSCT is a medical treatment in which abnormal hematopoietic cells, responsible for blood formation, are replaced with healthy cells from the bone marrow, umbilical cord blood, or peripheral blood of a donor or the patient's own hematopoietic cells following a preparative regimen, consisting of chemotherapy with/without radiation. HSCT is the second most common form of pediatric transplant, with more than 2,000 transplantations performed on patients younger than 20 years in 2008 (Center for International Blood and Marrow Transplant Research, 2005). HSCT is typically performed at specialized facilities and generally necessitates having a committed parent or primary caregiver in the weeks or months prior to, during, and posttransplant. The combination of isolation and a rigorous clinical course intensifies the stress associated with HSCT, placing a significant burden on the parent-child dyad.

\section{New Contribution}

Although previous research has pointed to the pivotal role of the parental caregiver in pediatric chronic care, parental activation on behalf of the child - the extension of a parents' 
self-efficacy into the management of their child's health-has never been conceptualized or studied. This study examines this essential component of chronic care in a gravely ill population of children undergoing HSCT, where parental participation in care is critical. As the first to characterize and investigate activation in this way, the results of our study of a pediatric HSCT sample offer novel insights into what influences parental activation in complex pediatric care.

\section{Conceptual Framework}

We use a process model for predicting parenting behaviors developed by Jay Belsky (1984). The Belsky model asserts that parenting is influenced by three general forces, listed in order of greatest to least impact: the parent's personality, the social environment surrounding the parent-child relationship, and characteristics of the child. In a recent article, Belsky's process model was employed to identify predictors of parental self-efficacy (PSE) in mothers and fathers of toddlers (Sevigny \& Loutzenhiser, 2010). This article highlighted differences in maternal and paternal models, but supported the ordered importance of parent personality, social factors, and child characteristics in determining PSE. Multiple studies have identified a significant association between an individual's patient activation and selfefficacy (Salonen et al., 2009; Skolasky et al., 2008; Skolasky, Mackenzie, Riley, \& Wegener, 2009); therefore, because of the success of the Belsky model in characterizing PSE, we elected to use the model to explore determinants of parental activation on behalf of the child.

Potential determinants of parental activation were derived from previous studies describing parent, social, and child-related factors that mediate parental self-efficacy. Sevigny and Loutzenhiser (2010) showed that higher PSE is predicted by higher general self-efficacy and better family functioning in mothers and lower parenting stress and better family functioning in fathers. In parents of newborn infants, predictors of high parental self-efficacy included being a female parent, greater parity, and better self-concept; predictors of low self-efficacy included health problems of the child and depression in the parent (Salonen et al., 2009). In mothers of autistic children, higher maternal self-efficacy was related to greater time elapsed since the child's diagnosis (Kuhn \& Carter, 2006). It has also been shown that maternal depression is predictive of lower maternal self-efficacy relating to the care of a child with asthma (Bartlett et al., 2004). Studies have revealed both positive and negative associations between PSE and marital status and parental stress. In the parental management of diabetes, one study showed that higher social stress is related to worse management (Parkerson, Broadhead, \& Tse, 1995), whereas another showed that higher diabetes-specific stress is related to better management (Stallwood, 2005). Similarly, whereas Sevigny and Loutzenhiser (2010) highlighted the association between better marital satisfaction and PSE, another study found that single parents had higher PSE (Bryanton, Gagnon, Hatem, \& Johnston, 2008).

Using these established relationships, we hypothesized that higher parental activation on behalf of the child would be predicted by better parent emotional functioning, greater parity, better general health of the child as assessed by the parent, and longer duration of the child's illness. Additionally, we hypothesized that a similar positive association may exist between 
a parent's self-activation and their activation on behalf of their child, reflecting the close link between self-efficacy and PSE (Bryanton et al., 2008; Sevigny \& Loutzenhiser, 2010). We also tested possible associations between parental activation on behalf of the child and social stress and marital status. All hypothesized predictor variables of patient activation that are predictors of PSE are summarized in Figure 1.

Because of the importance of a patient's personal, social, and disease factors in determining patient activation, potential predictors of parental activation on behalf of their chronically ill child were also drawn from predictors of patient activation in chronically ill adults.

Adhering to the Belsky model, predictors of self-activation were adapted and stratified to fit the three forces that influence parenting behaviors (Figure 1). All personal traits of chronically ill adults (age, general health, emotional functioning) and social factors (insurance, income, education level) that influence activation were identified as potential personal and social/environmental traits of parents that may influence their parental activation. Because our analysis pertains to chronically ill children, important disease characteristics that determine activation in chronically ill adults were identified as potentially predictive child characteristics; these included the duration of the child's illness and the child's general health as rated by the parent. Guided by the significance of age as a predictor of patient activation, we hypothesized that child age may be an important characteristic for determining parental activation. We also hypothesized that parental predictions about the future of the child's illness, termed parental forecasting, would be associated with parental activation; we elected to define parental forecasting as a child characteristic because it pertains directly to the child's illness.

The primary objective of this study is to answer the following question: What contributes to parental activation in the management of chronic pediatric illness? By employing a hierarchical linear regression model, we will also determine if the ordered importance of parent personal traits, social environment factors, and child characteristics, described by Belsky as contributing to parenting behaviors and confirmed by Sevigny as contributing to PSE, extends to parental activation in our population.

\section{Method}

\section{Participants}

Participants were 198 parent-child dyads involved in a larger, longitudinal, and randomized controlled study of children undergoing transplant and their parents (HSCT-CHESS ${ }^{\mathrm{TM}}$ ). The study investigated the efficacy of a web-based intervention, providing information and support resources for parents of children during the first 6 months after transplant. Parentchild dyads were recruited from six transplant centers across the United States and deemed eligible based on the following criteria for the parent: a working knowledge of English, minimum age of 18 years, and status as the child's primary caregiver. All children included in the study were between 2 months and 18 years old at the time of transplantation. To participate in the study, all parent-child dyads were required to complete a set of baseline measures before the start of the preparative regimen and all patients were required to proceed to transplant. HSCT-CHESS was approved by the Tufts Medical Center Institutional Review Board (IRB) and the IRBs of the participating sites. 
Demographic variables-Demographic variables were obtained from parents on age and gender of both dyad members. In addition, information on parent race/ethnicity, parental marital status, parent educational level, number of siblings in the household, type of insurance, and annual household income was also collected.

Medical assessment variables-Baseline medical information was collected by trained study staff, using standardized medical chart review forms developed for the study. Variables included causal diagnosis (malignant or nonmalignant) and duration of illness. Type of HSCT (autologous, allogeneic related, allogeneic unrelated) was also collected, together with other transplant-specific factors.

\section{Patient Activation Measure (PAM) and Parent Patient Activation Measure} (Parent-PAM)-The primary outcomes of this study were parental activation regarding their own health and parental activation concerning their child's health. The 13-item short form of the PAM was used to assess parent self-activation by determining the parent's knowledge, confidence, and willingness to act regarding their own health (Hibbard, Mahoney, Stockard, \& Tusler, 2005). The PAM is validated in chronically-ill populations (Fowles et al., 2009; Hibbard et al., 2004; Hibbard \& Cunningham, 2008; Mosen et al., 2007; Rask et al., 2009; Skolasky et al., 2008; Stepleman et al., 2010). In healthy populations, the PAM has also been validated as a measure of "consumer" activation (Fowles et al., 2009; Hibbard \& Cunningham, 2008; Hibbard, Peters, Dixon, \& Tusler, 2007; Terry \& Xi, 2010).

Parental activation on behalf of their child was assessed using a novel version of the short form of the PAM developed by its authors and used in this study with their permission. The Parent-PAM, which reframed all items to ask parents to assess their knowledge, confidence, and willingness to act concerning their child's health, was used to assess the parent's activation in the management of their child's illness. The 13 items of the Parent-PAM are included in Table 1. These may be compared to the 13 items of the PAM published by Hibbard et al. (2005, p. 1923, table 1) in their article "Development and Testing of a Short Form of the Patient Activation Measure." The items in both measures are scored on a Likerttype scale with four different response options of varying agreement (from $1=$ disagree strongly to $4=$ agree strongly). All responses are summed and scaled from 0 to 100, based on a conversion chart provided by the developers of the measure (Insignia Health, 2007). This yields an activation score where higher scores correspond to higher activation. PAM and Parent-PAM scores were also stratified into the following outlined "levels of activation": Level 1-does not believe the patient or caregiver role is important (score $\leq 47.0$ ), Level 2-does not have the confidence or skill to take action (score $\geq 47.1$ and 55.1), Level 3-may begin to take action (score 255.2 and 567.0), or Level 4-takes action, but may have difficulty maintaining behaviors over time (score 267.1 ; Mosen et al., 2007).

Child Health Ratings Inventories (CHRIs)-general health-This well-validated measure of HRQL in both children undergoing pediatric HSCT and a parent (Parsons et al., 
2005; Parsons et al., 2006) consists of 20 items, each using a 5-point Likert-type scale. These items assess three domains of general functioning: physical, emotional, and role. Additionally, two single items separately assess general health and overall well-being. The scores are transformed to a 0 to 100 point scale, where higher scores indicate greater functioning and health status.

Baseline Forecasting Scale-In addition to the HRQL items discussed above, the CHRIs-general parent report also assesses the parent's predictions about their child's illness in the future, representing "forecasting." All items in the scale are scored on a 5-point Likert-type scale (higher $=$ more positive outlook). These items were evaluated to determine if they formed a psychometrically robust scale. While the internal consistency reliability of the five-item scale was $<.70$, we identified one item that adversely affected the scale's performance using the deleted item method. Removal of the item stating "My child resists illness very well" raised the alpha coefficient above the minimum acceptable value of .70; the "forecasting score" was determined by the remaining four items. This scale was used to test the relationship between parental predictions of their child's future health with reported levels of activation.

The Duke Stress Scale (DUSOCS)—The DUSOCS is a validated measure (Parkerson et al., 1989; Parkerson, Broadhead, \& Tse, 1991) that is used to assess social stress. Summary scores are generated where higher scores indicate greater social stress.

\section{Statistical Analyses}

Demographic and clinical characteristics were described for the study sample using means (standard deviations $[S D]$ ), medians (25th-75th percentile), frequencies, and percentages. Descriptive statistics were then calculated for each version of the PAM, and individual PAM and Parent-PAM scores were stratified into the appropriate level of activation. Results were compared with results from a national sample, conducted by the instrument's author (Hibbard et al., 2005). Internal consistency reliability (ICR) was calculated using Cronbach's alpha coefficient (Cronbach \& Warrington, 1951).

Univariate analyses were performed to assess hypothesized associations between ParentPAM and parental demographic and HRQL traits (age, general health, emotional functioning, and PAM score), social and environmental traits of the family (type of insurance, number of siblings in household, marital status of parent, and parent's social stress), and demographic, HRQL, and disease-related characteristics of the child (age, parent's forecasting of child's future health, parent's rating of child's general health, and duration of the child's illness). For the duration of illness variable, the log transformation was used because the data for this variable were not normally distributed. Two-sample $t$ tests (for binary variables), analysis of variance (for categorical variables), or Pearson's correlation (for continuous variables) were used to determine the significance of association between each variable and Parent-PAM scores.

To measure agreement between stratified PAM and Parent-PAM levels, the weighted kappa coefficient ( $\kappa$ ) with a 95\% asymptotic confidence interval was calculated. The following guidelines are suggested to interpret the strength of agreement indicated by different kappa 
values: $\kappa<0.0$, poor; $\kappa=0.00-0.20$, slight; $\kappa=0.21-0.40$, fair; $\kappa=0.41-0.60$, moderate; $\kappa$ $<0.61-0.80$, substantial; $\kappa=0.81-1.00$, almost perfect (Feinstein, 1985).

Model for the Parent-PAM-Hierarchical multiple regression analyses were performed to construct a model for parental activation concerning their child's health. In accordance with the Belsky model for parenting behaviors, potential predictors were divided into three blocks (Belsky, 1984). The first block which was entered contained variables pertaining to demographic and health-related traits of the parent; the second block contained variables pertaining to the social or environmental traits of the family; the final block contained variables pertaining to demographic, health-related, and disease-related characteristics of the child. Both change in $R^{2}$ and change in $F$ statistic were calculated after the entry of each block. Blocks for which the change in $F$ statistic was not significant $(p>.05)$ were subsequently removed to form the final multivariate model.

\section{Results}

\section{Participant and Patient Characteristics}

The sample included a total of 198 parent-child dyads, with parent median age of 38 years (25th-75th percentile, 33-45) and a child median age of 8 years (25th-75th percentile, 414 ) at the time of transplant (Table 2). The parents were predominantly female (81.8\%), White and non-Hispanic (69.7\%), had obtained some college education $(72.7 \%)$, and were married or living with a partner $(83.8 \%)$. The majority of families had private insurance $(68.0 \%)$ and at least one other child living in the home (76.8\%). The median duration of the child's illness prior to transplant was 11 months (25th-75th percentile, 6-41 months). Transplants were predominantly allogeneic from unrelated donors (55.6\%), with the remaining patients split between allogeneic transplants from related donors (19.2\%) and autologous transplants (25.3\%); 61.6\% were for malignancies.

\section{PAM and Parent-PAM}

Both the PAM $(N=197)$ and Parent-PAM $(N=198)$ demonstrated acceptable ICR within our sample (PAM, $\alpha=.86$; Parent-PAM $a=.85$ ). The average PAM and Parent-PAM scores were almost identical, $68.6(S D=16.7)$ and $68.6(S D=15.5)$, respectively. Both of these results are higher than the average PAM score of 61.9, observed in the national sample used to establish the measure (Hibbard et al., 2005). Regarding the distribution of PAM scores across the four outlined levels of activation (Mosen et al., 2007), a much greater percentage of parents in our sample was concentrated in the fourth level of activation than in the national sample ( $47.2 \%$ vs. $22.3 \%$, respectively). Generally, an upward shift in level of parental self-activation (indicated by PAM score) was observed in our sample, with only $18.3 \%$ being restricted to the first two levels of activation. Regarding the distribution of Parent-PAM, scores were similarly concentrated in the fourth and highest level of activation (52.5\%; Table 3).

Univariate comparison of PAM and Parent-PAM scores revealed a highly significant correlation between the two scores $(r=.55, p<.0001)$. However, the strength of agreement 
between PAM and Parent-PAM levels was fair $(\kappa=0.28,95 \%$ confidence interval $[\mathrm{CI}]=$ $0.17-0.38$; Table 3).

\section{Hierarchical Multiple Regression Model for the Parent-PAM}

Prior to the construction of the multivariate model for parental activation on behalf of their child, univariate analyses were performed assessing relationships between Parent-PAM scores and specific parental traits, social-environmental traits, and child characteristics selected by a priori hypotheses (Table 4). No significant associations were found between Parent-PAM score and any social-environmental traits of the parent or family. Highly significant associations $(p<.0001)$ were observed between higher Parent-PAM score and higher PAM score and longer duration of illness.

Following the Belsky process model, hierarchical multiple regression analysis was then used to construct a preliminary model for Parent-PAM score. All results of preliminary analyses are presented in Table 4 . The first block added to the model included demographic and personal traits of the parent. This block was highly significant, $\Delta F(4,192)=25.90, p<$. 0001 , accounting for $34 \%$ of the variance observed. Within the block, statistically significant associations were observed between higher Parent-PAM score and higher PAM score $(\beta=$ $0.55, p<.0001)$ and younger parent age $(\beta=-0.25, p=.03)$. The second block added to the model included social-environmental traits of the parent and family. Although a significant association was observed between higher Parent-PAM score and higher social stress ( $\beta=$ $0.19, p=.007)$, the addition of this block was not statistically significant, $\Delta F(5,187)=1.75$, $p=.13$, and only accounted for an additional $2 \%$ of the variance. The third and final block added included demographic, health-related, and disease-specific characteristics of the pediatric HSCT recipient. The addition of this block was statistically significant, $\Delta F(4,183)$ $=3.86, p=.005$, accounting for an additional $5 \%$ of the variance in Parent-PAM score. Within the block, a highly significant association was observed between higher Parent-PAM score and longer duration of the child's illness prior to transplant $(\beta=0.26, p<.0001)$.

To construct the final multivariate model (Table 5), the nonsignificant block containing social-environmental traits was removed and our analysis was repeated. The final model was statistically significant, $\Delta F(8,188)=15.24, p<.0001$, accounting for $37 \%$ of the variance in Parent-PAM score. Within the final model, highly significant associations were observed between higher Parent-PAM score and higher PAM score $(\beta=0.53, p<.0001)$ and longer duration of the child's illness ( $\beta=2.47, p=.001$ ), while marginally significant associations were observed between higher Parent-PAM score and younger parent age ( $\beta=$ $-0.36, p=.02)$ and lower rating by the parent of their own general health $(\beta=-0.09, p=$. $04)$.

\section{Discussion}

In this study, we examine the demographic, clinical, social-environmental, and psychosocial factors associated with parental activation concerning their child's health in parent-child dyads prior to HSCT. Parent activation concerning their child's health has not been previously explored. Therefore, this study is a crucial step in determining how to best understand the self-management behaviors of parents of children approaching a life- 
threatening treatment and rigorous recovery course. Our hierarchical multivariate regression model, constructed around the Parent-PAM, identifies parental activation on behalf of the child as a distinct construct, related to but different from both patient activation in chronically ill populations and parenting self-efficacy.

Using the Belsky process model for describing parenting behaviors, predictors of parental activation on behalf of the child in our sample were identified that aligned with and diverged from predictors of parenting self-efficacy and patient activation in other populations (Belsky, 1984). Higher parent activation regarding their child's health was observed in younger parents, those who reported higher activation on behalf of their own health care, and those whose children had been ill for a longer period of time. The importance of age and duration of illness mirror findings from previous studies of parenting self-efficacy (Kuhn \& Carter, 2006; Sevigny \& Loutzenhiser, 2010) and patient activation (Hibbard \& Cunningham, 2008; Rask et al., 2009). However, the absence of significant associations between higher Parent-PAM score and several other known predictors of PAM score and PSE reveal important distinctions between the constructs. Specifically, diverging from the Belsky model and its adaptation to PSE (Sevigny \& Loutzenhiser, 2010), no significant relationship was observed between parent activation on behalf of the child and any social, environmental, or familial variables. While other studies have highlighted associations between PSE, parity, and marital status, none of these relationships extended to the ParentPAM in our sample (Bryanton et al., 2008; Kuhn \& Carter, 2006; Salonen et al., 2009; Sevigny \& Loutzenhiser, 2010). Similarly, in contrast to other studies identifying associations between higher patient activation and higher education, higher income, and having private insurance (Hibbard \& Cunningham, 2008; Lubetkin et al., 2010), our analysis revealed no significant relationship between parental activation on behalf of their child and socioeconomic status.

Furthermore, although the block including personal characteristics of the parent was highly significant in the Parent-PAM model, no positive associations were observed between Parent-PAM score and any measure of parent HRQL. This differs from several previous studies outlining significant positive associations between patient activation and self-rated general health (Hibbard \& Cunningham, 2008; Lubetkin et al., 2010; Stepleman et al., 2010) and emotional functioning (Mosen et al., 2007), as well as positive associations between parenting self-efficacy and emotional functioning (Bartlett et al., 2004; Kuhn \& Carter, 2006; Salonen et al., 2009).

The final Parent-PAM model suggests two potential explanations for how parental activation concerning their child's health is determined in the HSCT parent population. In one sense, the data implicate the high importance of the chronicity of the child's illness in determining the parent's Parent-PAM score. It is thought that parents of children who have been sick for a greater period of time would feel more experienced in advocating for their child and more prepared for the demands of the transplant. Rask et al. (2009) found that duration of illness was significantly associated with patient activation. Similar to our findings, that study also found no significant correlation between HRQL and patient activation. This suggests that in certain populations, higher activation may be determined more by specific personal experience and less by the patient's or parent's emotional state. 
Alternatively, the nonsignificance of the parent's emotional functioning in our model, the association between worse general health and higher Parent-PAM, and the association between higher social stress and higher Parent-PAM in univariate calculations and the preliminary model suggest that a combination of stressors with high threat may "prime" high activation on behalf of the child. Using sources of stress as motivational factors, parents may achieve higher activation by channeling their stress into engagement in providing the fullest level of care for their child. The benefit or detriment of this reaction is difficult to discern. Previous studies have suggested that when reacting to chronic illness in their children, parents' natural protective instincts may manifest as "benevolent overreaction" (Murray \& Haynes, 1996). A recent study showed a positive association between more protective parent behaviors and increased functional disability in pediatric patients with chronic illness (Claar, Guite, Kaczynski, \& Logan, 2010), demonstrating the potentially negative effect of overly active parents. Thus, it may be possible that parents with the highest Parent-PAM scores are "overly activated," willing to do anything for the sake of their children without complete consideration of their own limitations or health. It may also be possible that these parents at baseline exhibit strong self-management behaviors of their child's illness as a reflexive response to high stress or perceived threat to life.

We acknowledge this study's limitations. Foremost, although the Parent-PAM exhibited an acceptable ICR in our sample, further studies are needed to establish the validity of the measure in other populations. Parent-PAM scores were also much higher in our sample than PAM scores reported by chronically-ill patients or healthy consumers in previous studies (Deen, Lu, Rothstein, Santana, Gold, 2010; Hibbard \& Cunningham, 2008; Skolasky et al., 2008; Stepleman et al., 2010), and although Parent-PAM and PAM scores were highly correlated in our sample $(r=.55, p<.0001)$, agreement between the level distributions of the two measures was only fair $(\kappa=0.28,95 \% \mathrm{CI}=0.17-0.38)$. Because of the skewed distribution of PAM and Parent-PAM scores to the highest level, we were unable to explore adequately potential factors explaining lower versus higher levels of activation, relying instead on analyses of continuous scores. Further studies are needed to test the validity of stratifying the Parent-PAM into the four outlined levels. Additionally, in comparison to other studied populations, the pediatric HSCT parents were predominantly younger, more privately insured, and more educated. Given the relative homogeneity within our sample, we may not have been able to identify specific factors associated with varying activation scores. Thus, further studies would be required to understand activation in demographically similar and dissimilar populations. Additionally, future studies are required to determine whether or not the constructed model for parent activation on behalf of the child in the specific case of pediatric HSCT parent-child population is generalizable to parent-child dyads dealing with other childhood conditions. The high ceiling effect observed in both PAM and Parent-PAM scores was identified as another limitation because it raises some questions about the measure's ability to establish a useful baseline for improvement over time. However, while it is notable that nearly $80 \%$ of parents reported Parent-PAM scores in the third and fourth levels, the remaining $20 \%$ did not. Early identification of such individuals might offer potential for future improvement initiatives. The information presented only reflects baseline assessments of PAM, Parent-PAM, and other relevant measures. Subsequent analyses are planned to focus on changes parental activation on behalf of the child over time. Finally, 
these results must be interpreted with caution since it is not known how dyads not enrolled perceive their activation levels at the time of HSCT.

In sum, our study is the first to describe parent activation on behalf of their child (the patient) within the context of a medically and psychologically demanding treatment, such as HSCT. Importantly, these results will be compared in planned analyses to 6-month assessments of the same parent-child dyads using the same measures, shedding new light on the impact of time and the intercurrent clinical course on this form of activation.

\section{Acknowledgments}

Funding

The authors disclosed receipt of the following financial support for the research, authorship, and/or publication of this article:

Funding for this study was provided from the National Cancer Institute (R01 CA 119196, SKP).

\section{References}

Bandura A. Self-efficacy mechanism in human agency. American Psychologist. 1982; 37:122-147.

Bartlett SJ, Krishnan JA, Riekert KA, Butz AM, Malveaux FJ, Rand CS. Maternal depressive symptoms and adherence to therapy in inner-city children with asthma. Pediatrics. 2004; 113:229237. [PubMed: 14754931]

Belsky J. The determinants of parenting: A process model. Child Development. 1984; 55:83-96. [PubMed: 6705636]

Best M, Streisand R, Catania L, Kazak AE. Parental distress during pediatric leukemia and posttraumatic stress symptoms (PTSS) after treatment ends. Journal of Pediatric Psycholology. 2001; 26:299-307.

Bodenheimer T, Lorig K, Holman H, Grumbach K. Patient self-management of chronic disease in primary care. Journal of the American Medical Association. 2002; 288:2469-2475. [PubMed: 12435261]

Bollinger LM, Nire KG, Rhodes MM, Chisolm DJ, O'Brien SH. Caregivers' perspectives on barriers to transcranial Doppler screening in children with sickle-cell disease. Pediatric Blood \& Cancer. 2011; 56:99-102. [PubMed: 20842753]

Bryanton J, Gagnon AJ, Hatem M, Johnston C. Predictors of early parenting self-efficacy: Results of a prospective cohort study. Nursing Research. 2008; 57:252-259. [PubMed: 18641494]

Center for International Blood and Marrow Transplant Research. Statistical Center of the Center for International Blood and Marrow Transplant Research. Milwaukee, WI: Author; 2005. Retrieved from http://www.cibmtr.org

Claar RL, Guite JW, Kaczynski KJ, Logan DE. Factor structure of the adult responses to children's symptoms: Validation in children and adolescents with diverse chronic pain conditions. Clinical Journal of Pain. 2010; 26:410-417. [PubMed: 20473048]

Cronbach LJ, Warrington WG. Time-limit tests: Estimating their reliability and degree of speeding. Psychometrika. 1951; 16:167-188. [PubMed: 14844557]

Deen D, Lu WH, Rothstein D, Santana L, Gold MR. Asking questions: The effect of a brief intervention in community health centers on patient activation. Patient Education and Counseling. 2010; 84:257-260. [PubMed: 20800414]

Donald M, Ware RS, Ozolins IZ, Begum N, Crowther R, Bain C. The role of patient activation in frequent attendance at primary care: A population-based study of people with chronic disease. Patient Education and Counseling. 2010; 83:217-221. [PubMed: 20598825]

Feinstein, AR. The architecture of clinical epidemiology. Philadelphia: WB Saunders and Company; 1985. 
Fowles JB, Terry P, Xi M, Hibbard J, Bloom CT, Harvey L. Measuring self-management of patients' and employees' health: Further validation of the Patient Activation Measure (PAM) based on its relation to employee characteristics. Patient Education and Counseling. 2009; 77:116122.10.1016/j.pec.2009.02.018 [PubMed: 19356881]

Han K, Lee P, Lee S, Park E. Factors influencing quality of life in people with chronic illness in Korea. Journal of Nursing Scholarship. 2003; 35:139-144. [PubMed: 12854294]

Hibbard JH, Cunningham PJ. How engaged are consumers in their health and health care, and why does it matter? Research Briefs. 2008; 8:1-9. [PubMed: 18946947]

Hibbard JH, Mahoney ER, Stockard J, Tusler M. Development and testing of a short form of the patient activation measure. Health Services Research. 2005; 40:1918-1930.10.1111/j. 1475-6773.2005.00438.x [PubMed: 16336556]

Hibbard JH, Peters E, Dixon A, Tusler M. Consumer competencies and the use of comparative quality information: It isn't just about literacy. Medical Care Research and Review. 2007; 64:379-394. [PubMed: 17684108]

Hibbard JH, Stockard J, Mahoney ER, Tusler M. Development of the Patient Activation Measure (PAM): Conceptualizing and measuring activation in patients and consumers. Health Services Research. 2004; 39:1005-1026. [PubMed: 15230939]

Insignia Health. Patient Activation Measure (PAM) license package. Portland, OR: Author; 2007.

Kuhn JC, Carter AS. Maternal self-efficacy and associated parenting cognitions among mothers of children with autism. American Journal of Orthopsychiatry. 2006; 76:564-575. [PubMed: 17209724]

Lorig KR, Ritter PL, Jacquez A. Outcomes of border health Spanish/English chronic disease selfmanagement programs. Diabetes Educator. 2005; 31:401-409. [PubMed: 15919640]

Lubetkin EI, Lu WH, Gold MR. Levels and correlates of patient activation in health center settings: Building strategies for improving health outcomes. Journal of Health Care for the Poor and Underserved. 2010; 21:796-808. [PubMed: 20693726]

Mosen DM, Schmittdiel J, Hibbard J, Sobel D, Remmers C, Bellows J. Is patient activation associated with outcomes of care for adults with chronic conditions? Journal of Ambulatory Care Management. 2007; 30:21-29. [PubMed: 17170635]

Murray JA, Haynes MP. The benevolent overreaction: Nursing assessment and intervention in families coping with seizure disorder. Journal of Neuroscience Nursing. 1996; 28:252-258. [PubMed: 8880599]

Osborne RH, Wilson T, Lorig KR, McColl GJ. Does self-management lead to sustainable health benefits in people with arthritis? A 2-year transition study of 452 Australians. Journal of Rheumatology. 2007; 34:1112-1117. [PubMed: 17343319]

Parkerson GR Jr, Broadhead WE, Tse CK. Validation of the Duke Social Support and Stress Scale. Family Medicine. 1991; 23:357-360. [PubMed: 1884930]

Parkerson GR Jr, Broadhead WE, Tse CK. Perceived family stress as a predictor of health-related outcomes. Archives of Family Medicine. 1995; 4:253-260. [PubMed: 7881608]

Parkerson GR Jr, Michener JL, Wu LR, Finch JN, Muhlbaier LH, Magruder-Habib K, Chen AL. Associations among family support, family stress, and personal functional health status. Journal of Clinical Epidemiology. 1989; 42:217-229. [PubMed: 2785165]

Parsons SK, Shih MC, DuHamel KN, Ostroff J, Mayer DK, Austin J, Manne S. Maternal perspectives on children's health-related quality of life during the first year after pediatric hematopoietic stem cell transplant. Journal of Pediatric Psychology. 2006; 31:1100-1115. [PubMed: 16150874]

Parsons SK, Shih MC, Mayer DK, Barlow SE, Supran SE, Levy SL, Kaplan SH. Preliminary psychometric evaluation of the Child Health Ratings Inventories (CHRIs) and Disease-Specific Impairment Inventory-HSCT (DSII-HSCT) in parents and children. Quality of Life Research. 2005; 14:1613-1625. [PubMed: 16110940]

Rask KJ, Ziemer DC, Kohler SA, Hawley JN, Arinde FJ, Barnes CS. Patient activation is associated with healthy behaviors and ease in managing diabetes in an indigent population. Diabetes Educator. 2009; 35:622-630. [PubMed: 19419972]

Salonen AH, Kaunonen M, Åstedt-Kurki P, Järvenpää AL, Isoaho H, Tarkka MT. Parenting selfefficacy after childbirth. Journal of Advanced Nursing. 2009; 65:2324-2336. [PubMed: 19761456] 
Schnell-Hoehn KN, Naimark BJ, Tate RB. Determinants of self-care behaviors in community-dwelling patients with heart failure. Journal of Cardiovascular Nursing. 2009; 24:40-47. [PubMed: 19114800]

Sevigny PR, Loutzenhiser L. Predictors of parenting self-efficacy in mothers and fathers of toddlers. Child: Care, health and development. 2010; 36:179-189.

Shigaki C, Kruse RL, Mehr D, Sheldon KM, Bin G, Moore C, Lemaster J. Motivation and diabetes self-management. Chronic Illness. 2010; 6:202-214. [PubMed: 20675362]

Simmons KL, Smith JA, Bobb KA, Liles LL. Adjustment to colostomy: Stoma acceptance, stoma care self-efficacy and interpersonal relationships. Journal of Advanced Nursing. 2007; 60:627-635. [PubMed: 18039249]

Skolasky RL, Mackenzie EJ, Riley LH III, Wegener ST. Psychometric properties of the Patient Activation Measure among individuals presenting for elective lumbar spine surgery. Quality of Life Research. 2009; 18:1357-1366. [PubMed: 19916057]

Skolasky RL, Mackenzie EJ, Wegener ST, Riley LH III. Patient activation and adherence to physical therapy in persons undergoing spine surgery. Spine (Phila Pa 1976). 2008; 33:E784-E791. [PubMed: 18827683]

Stallwood L. Influence of caregiver stress and coping on glycemic control of young children with diabetes. Journal of Pediatric Health Care. 2005; 19:293-300. [PubMed: 16202837]

Stepleman L, Rutter MC, Hibbard J, Johns L, Wright D, Hughes M. Validation of the patient activation measure in a multiple sclerosis clinic sample and implications for care. Disability and Rehabilitation. 2010; 32:1558-1567.10.3109/09638280903567885 [PubMed: 20590506]

Terry PE, Xi M. An examination of presenteeism measures: The association of three scoring methods with health, work life, and consumer activation. Population Health Management. 2010; 13:297307. [PubMed: 21174602]

Tucker CM, Butler AM, Loyuk IS, Desmond FF, Surrency SL. Predictors of a health-promoting lifestyle and behaviors among low-income African American mothers and white mothers of chronically ill children. Journal of the National Medical Association. 2009; 101:103-110. [PubMed: 19378625]

Wagner EH, Austin BT, Davis C, Hindmarsh M, Schaefer J, Bonomi A. Improving chronic illness care: Translating evidence into action. Health Affairs (Millwood). 2001; 20:64-78.

Warren-Findlow J, Seymour RB, Shenk D. Intergenerational transmission of chronic illness self-care: Results from the caring for hypertension in African American families study. The Gerontologist. 2010; 51:64-75. [PubMed: 20864590]

\section{Appendix}

\section{HSCT-CHESS}

\section{Central Project Staff}

Tufts Medical Center, Boston, MA: Susan K. Parsons, MD, MRP, Principal Investigator; Sara J. Ratichek, MA, Project Director; Ruth Ann Weidner, MBA, MRP, Data Management Director; Norma Terrin, PhD, Senior Statistician; Angie Mae Rodday, MS, Statistician; Tanya Bernstein, MPH, Research Associate; Doris Hernandez, Research Assistant; Elizabeth J. Pedowitz, Research Assistant; Brian W. Pennarola, Research Assistant

Web Development Team: David H. Gustafson, PhD, Co-Investigator; Fiona McTavish (Center for Health Enhancement System Studies, University of Wisconsin, Madison); Susan Stewart (BMT InfoNet, Highland Park, IL); Deborah Mayer, PhD, RN (University of North Carolina, Chapel Hill, NC) 


\section{Site Principal Investigators and Study Staff}

Dana-Farber Cancer Institute, Boston, MA: Eva Guinan, MD, Principal Investigator; Nicholas Domaney, Study Coordinator; Janice D. Russell, Study Coordinator; Lisa Brennan, RN, Research Nurse

Medical College of Wisconsin, Milwaukee, WI: Mary Jo Kupst, PhD, Principal Investigator; Kristin Bingen, PhD, Co-Principal Investigator and Study Coordinator; Rose Lucey, Study Administrator

City of Hope National Medical Center, Duarte, CA: Sunita Patel, PhD, Principal Investigator; Joseph Rosenthal, MD, Site Consultant; Colleen Keilty, Study Coordinator

Fred Hutchinson Cancer Research Center, Seattle, WA: Karen L. Syrjala, PhD, Principal Investigator; Samantha Artherholt, PhD and Allison Stover, MPH, Study Coordinators; Debra Bernard, MCR Data Abstractor; Eun-Ju Lee, Study Assistant

Cincinnati Children's Hospital Medical Center, Cincinnati, OH: Stella Davies, MBBS, $\mathrm{PhD}$, Principal Investigator; Elizabeth Smith, Study Coordinator; Sharon Penko, Study Coordinator; Sonata Joderle, MD, MCR Data Abstractor

Children's Hospital of Philadelphia, Philadelphia, PA: Lisa Schwartz, PhD, Principal Investigator; Ifigenia Mougianis and Heather Hussey, MPH, Study Coordinators 


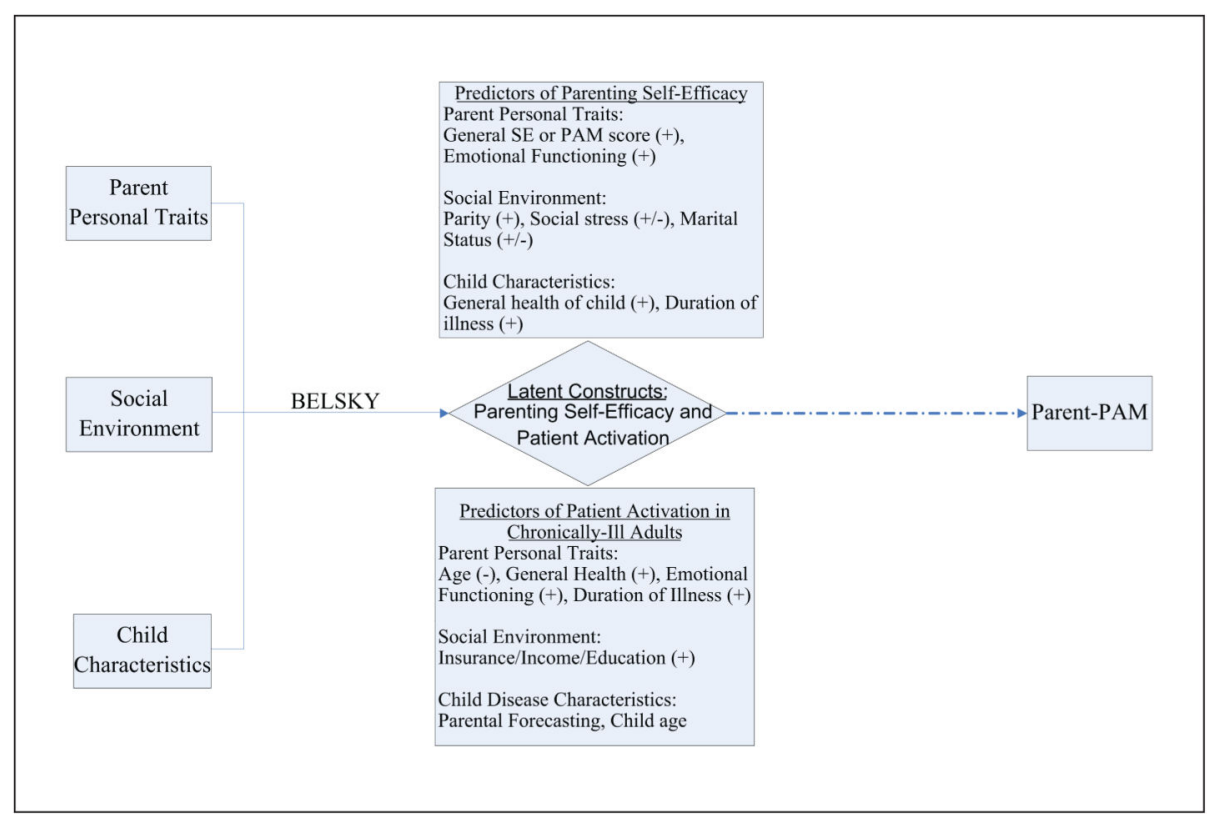

Figure 1.

Conceptual process model for determining parent activation on behalf of the child Note: "+" indicates that previous studies have shown a positive association between either patient activation or parenting self-efficacy and a particular predictor; “-” indicates a negative association shown. 


\section{Table 1}

\section{List of Items for the Parent Patient Activation Measure}

When all is said and done, I am the person who is responsible for managing my child's health condition.

Taking an active role in my child's health care is the most important factor in determining his/her health and ability to function.

I am confident that I can take actions that will help prevent or minimize some symptoms or problems associated with my child's health condition.

I know what each of my child's prescribed medications does.

I am confident that I can tell when I need to go get medical care and when I can handle my child's health problem myself.

I am confident I can tell a doctor the concerns that I have about my child's health, even when he or she does not ask.

I am confident that I can follow through on medical treatments I need to do for my child at home.

I understand the nature and causes of my child's health condition(s).

I know the different medical treatment options available for my child's health condition.

I have been able to help my child maintain the recommended lifestyle changes (like diet or exercise) for his/her condition.

I know how to prevent further problems with my child's health condition.

I am confident I can figure out solutions when new situations arise with my child's health condition.

I am confident that I can help my child maintain lifestyle changes, like diet and exercise, even during times of stress.

Source: Insignia Health Patient Activation Measure; Copyright @ $2003-2005$, University of Oregon. All rights reserved. Contact Insignia Health at www.insigniahealth.com. Copyright @ 2 2003, University of Oregon, Judith H. Hibbard, DrPH. 
Table 2

Demographics and Clinical Characteristics of Hematopoietic Stem Cell Transplant Recipients and Their Parents $(N=198)$

\begin{tabular}{|c|c|}
\hline Variable & Median (25th-75th) ${ }^{a}$ or $n(\%)$ \\
\hline \multicolumn{2}{|l|}{ Parent demographics } \\
\hline Age in years, median (25th-75th) ${ }^{a}$ & $38(33-45)$ \\
\hline \multicolumn{2}{|l|}{ Gender, $n(\%)$} \\
\hline Female & $162(81.8)$ \\
\hline Male & $36(18.2)$ \\
\hline \multicolumn{2}{|l|}{ Race/ethnicity, $n(\%)$} \\
\hline White, non-Hispanic & $138(69.7)$ \\
\hline Non-White, non-Hispanic & $25(12.6)$ \\
\hline Hispanic & $30(15.2)$ \\
\hline Other $b$ & $5(2.5)$ \\
\hline \multicolumn{2}{|l|}{ Level of education, $n(\%)$} \\
\hline High school graduate or less & $54(27.3)$ \\
\hline Some college or more & $144(72.7)$ \\
\hline \multicolumn{2}{|l|}{ Marital status, $n(\%)$} \\
\hline Married/living with partner & $166(83.8)$ \\
\hline Divorced/separated/widowed & $24(12.1)$ \\
\hline Never married & $8(4.0)$ \\
\hline \multicolumn{2}{|l|}{ Insurance type ${ }^{c}, n(\%)$} \\
\hline Private & $134(68.0)$ \\
\hline Public & $63(32.0)$ \\
\hline \multicolumn{2}{|l|}{ Child demographics } \\
\hline Age at transplant in years, median $\left(25^{\text {th }}-75\right.$ th $)$ & $8(4-14)$ \\
\hline \multicolumn{2}{|l|}{ Gender, $n(\%)$} \\
\hline Female & $87(43.9)$ \\
\hline Male & $111(56.1)$ \\
\hline \multicolumn{2}{|l|}{ Number of siblings at home, $n(\%)$} \\
\hline None & $46(23.2)$ \\
\hline One & $74(37.4)$ \\
\hline Two or more & $78(39.4)$ \\
\hline \multicolumn{2}{|l|}{ Clinical characteristics of the child } \\
\hline Duration of illness in months, median (25th-75th) ${ }^{a}$ & $11(5-41)$ \\
\hline Malignancy, $n(\%)$ & $122(61.6)$ \\
\hline \multicolumn{2}{|l|}{ Transplant type, $n(\%)$} \\
\hline Allogeneic, related & $38(19.2)$ \\
\hline Allogeneic, unrelated & $110(55.6)$ \\
\hline Autologous & $50(25.3)$ \\
\hline
\end{tabular}

Med Care Res Rev. Author manuscript; available in PMC 2014 September 11. 
${ }^{b}$ One self-identified as mixed race, one declined to state, and three stated that categories did not apply to them.

${ }^{c}$ Data on 197 subjects; one self-pay dyad. 
Table 3

Comparison of PAM and Parent-PAM Scores in Our HSCT Sample With the PAM National Sample

\begin{tabular}{|c|c|c|c|}
\hline & $\begin{array}{l}\text { PAM, National Sample } \\
\qquad(N=1469)\end{array}$ & $\begin{array}{l}\text { PAM, Our Sample }(N \\
=197)\end{array}$ & $\begin{array}{l}\text { Parent-PAM, Our } \\
\text { Sample }(N=198)\end{array}$ \\
\hline \multicolumn{4}{|l|}{ Summary statistics } \\
\hline Mean score $(S D)$ & 61.9 & $68.6(16.7)$ & $68.6(15.5)$ \\
\hline Cronbach's a ${ }^{b}$ & .91 & .86 & .85 \\
\hline PAM vs. Parent-PAM scores (Pearson $r$ ) & & \multicolumn{2}{|c|}{$.55, p<.0001$} \\
\hline \multicolumn{4}{|l|}{ Activation level distributions, $n(\%)$} \\
\hline $\begin{array}{l}\text { Level 1: Does not believe the patient or caregiver role is } \\
\text { important (score } \leq 47.0 \text { ) }\end{array}$ & $174(11.8)$ & $13(6.6)$ & $10(5.1)$ \\
\hline $\begin{array}{l}\text { Level 2: Lacks the confidence to take action (score, 47.1- } \\
55.1 \text { ) }\end{array}$ & $431(29.3)$ & $23(11.7)$ & $33(16.7)$ \\
\hline Level 3: May begin to take action (score, 55.2-67.0) & $536(36.5)$ & $68(34.5)$ & $51(25.8)$ \\
\hline $\begin{array}{l}\text { Level 4: Takes action, but may struggle to maintain } \\
\text { behaviors over time (score } \geq 67.1 \text { ) }\end{array}$ & $328(22.3)$ & $93(47.2)$ & $104(52.5)$ \\
\hline PAM vs. Parent-PAM level stratifications, $\kappa(95 \% \mathrm{CI})$ & & \multicolumn{2}{|c|}{$0.28[0.17,0.38]$} \\
\hline
\end{tabular}

Note: $\mathrm{PAM}=$ Patient Activation Measure; Parent-PAM = Parent Patient Activation Measure; HSCT = hematopoietic stem cell transplantation; $S D$ $=$ standard deviation; $\mathrm{CI}$, confidence interval.

${ }^{a}$ Patient Activation Measure (PAM) License Package, 2007.

$b_{a} \geq .70$, acceptable. 
Table 4

Preliminary Hierarchical Model for Parent-PAM Continuous Score

\begin{tabular}{|c|c|c|c|c|}
\hline Block/Variable & Pearson, $r$ or $p$ & $\beta(S E)$ & Adjusted $R^{2}$ Increase & $\Delta F(d f)$ \\
\hline \multicolumn{5}{|l|}{ Block 1: Parental traits } \\
\hline PAM & $.55^{* * *}$ & $0.55(0.06)^{* * *}$ & .34 & $25.90^{* * *}(4,192)$ \\
\hline CHRIs, parent emotional functioning & -.02 & $-0.08(0.05)$ & & \\
\hline Parent age & -.12 & $-0.25(0.11)^{*}$ & & \\
\hline CHRIs, parent's GH & -.03 & $-0.08(0.04)$ & & \\
\hline \multicolumn{5}{|c|}{ Blocks 1 and 2: Parental traits, social-environmental traits } \\
\hline PAM & - & $0.56(0.06)^{* * *}$ & .02 & $1.75(5,187)$ \\
\hline CHRIs, parent emotional functioning & - & $-0.04(0.05)$ & & \\
\hline Parent age & - & $-0.28(0.12)^{*}$ & & \\
\hline CHRIs, parent GH & - & $-0.08(0.04)$ & & \\
\hline DUSOCS, social stress & .10 & $0.19(0.07)^{* *}$ & & \\
\hline Insurance, private & $p=.50$ & $0.15(2.03)$ & & \\
\hline One sibling & $p=.19$ & $-1.65(2.40)$ & & \\
\hline Two siblings & $p=.51$ & $-0.18(2.41)$ & & \\
\hline Marital status, divorced & $p=.51$ & $0.00(2.85)$ & & \\
\hline \multicolumn{5}{|c|}{ Blocks 1, 2, and 3: Parental traits, social-environmental traits, child characteristics } \\
\hline PAM & - & $0.53(0.06)^{* * *}$ & .05 & $3.86^{* *}(4,183)$ \\
\hline CHRIs, parent emotional functioning & - & $-0.05(0.06)$ & & \\
\hline Parent age & - & $-0.39(0.15)^{*}$ & & \\
\hline CHRIs, parent GH & - & $-0.08(0.04)$ & & \\
\hline DUSOCS, social stress & - & $0.21(0.07)^{* *}$ & & \\
\hline Insurance, private & - & $-0.07(2.05)$ & & \\
\hline One sibling & - & $-2.89(2.37)$ & & \\
\hline Two siblings & - & $-1.29(2.38)$ & & \\
\hline Marital status, divorced & - & $-0.92(2.79)$ & & \\
\hline Child age & -0.01 & $0.09(0.21)$ & & \\
\hline CHRIs, parent forecasting & 0.00 & $.05(0.07)$ & & \\
\hline CHRIs, parent rating of child's GH & -0.04 & $.01(0.04)$ & & \\
\hline Duration of illness (log) & $0.26^{* * *}$ & $2.68(0.75)^{* * *}$ & & \\
\hline
\end{tabular}

Note: PAM = Patient Activation Measure; CHRI, Child Health Ratings Inventory; $d f=$ degrees of freedom; DUSOCS = Duke Stress Scale; GH = general health.

$*$

$p<.05$.

** $p<.01$.

$* * *$

$p<.001$. 
Table 5

Final Hierarchical Model for Parent-PAM Continuous Score

\begin{tabular}{lcccc}
\hline Variable & Pearson, $\boldsymbol{r}$ & $\boldsymbol{\beta}(\boldsymbol{S E})$ & Adjusted $\boldsymbol{R}^{\mathbf{2}}$ & $\boldsymbol{F}(\boldsymbol{d} \boldsymbol{f})$ \\
\hline Parental traits and child characteristics & & & \\
PAM & $.55^{* * *}$ & $0.53(0.06)^{* * *}$ & .37 & $15.24^{* * *}(8,188)$ \\
CHRIs, parent emotional functioning & -.02 & $-0.09(0.06)$ & $-0.36(0.15)^{*}$ \\
Parent age & -.12 & -.03 & $-0.09(0.04)^{*}$ \\
CHRIs, parent GH & -.01 & $0.07(0.21)$ \\
Child age & .00 & $0.06(0.07)$ \\
CHRIs, parent forecasting & -.04 & $0.02(0.03)$ \\
CHRIs, parent rating of child's GH & $.26^{* * *}$ & $2.46(0.74)^{* *}$ \\
Duration of illness (log) &
\end{tabular}

Note: PAM = Patient Activation Measure; CHRI = Child Health Ratings Inventory; $d f=$ degrees of freedom; GH = general health. $*$ p $<.05$.

$* *$ $\quad$ p $<.01$.

$* * * \quad p<.001$. 